\title{
Atomic , \\ Elemental Imaging of Alumina Ceramic Tube Using Laser Ablation- Inductively Coupled Plasma-Mass Spectrometry (LA-ICP-MS)
}

\author{
Qing $\mathrm{Li}^{\mathrm{a}}{ }^{\mathrm{a}}$ Yan Fang, ${ }^{\mathrm{a}}$ Jianghua Liu, ${ }^{\mathrm{c}}$ Chengrong Zhang, ${ }^{\mathrm{c}}$ and Zheng Wang a,b,* \\ a Shanghai Institute of Ceramics, Chinese Academy of Sciences, Shanghai 201899, P. R. China \\ ${ }^{b}$ Center of Materials Science and Optoelectronics Engineering, University of Chinese Academy of Sciences, Beijing, 100049, P. R. China \\ ${ }^{\mathrm{c}}$ Shengnuo Optoeletronic Technology (Qing Hai) Co., Ltd., Xining 810012, P. R. China
}

Received: January 21, 2021; Revised: April 05, 2021; Accepted: April 05, 2021; Available online: April 21, 2021.

DOI: $10.46770 / A S .2021 .019$

ABSTRACT: Laser ablation-inductively coupled plasma-mass spectrometry (LA-ICP-MS) is an attractive analytical technique for the direct analysis of samples found in the geology, biology, and the environmental and material sciences. However, few reports have discussed the difficulty found in the analysis of curved surface samples by LA-ICP-MS where the main focus is on the curved surface. In this work, LA-ICP-MS was used to map the elemental images of curved surface samples by segmentation and recombination. In addition, the influence of parameters, such as laser spot size, laser fluence, repetition rate, scan speed, dwell time and washout time on lateral resolution were investigated. The developed method was applied to the imaging analysis of lanthanum in an alumina ceramic tube, and the results showed that lanthanum was not uniformly distributed in the tube.

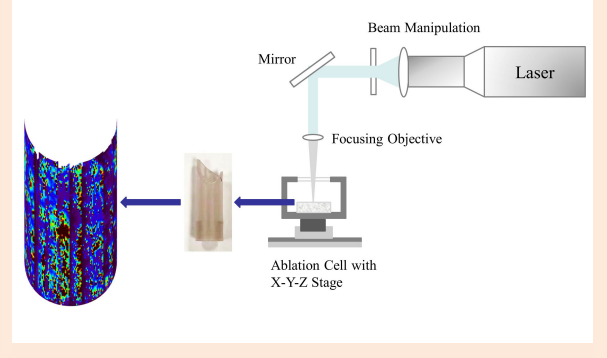

\section{INTRODUCTION}

Alumina ceramics are widely used in the energy, aerospace, machinery, automobile, metallurgy, chemical industries, as well as in the electronics and other fields because of their excellent properties of high temperature resistance, wear resistance, corrosion resistance, erosion resistance, and oxidation resistance. In order to improve the mechanical, electrical, optical or thermal properties of alumina ceramics, additives are usually added to improve sintering, densification, microstructure and crystal phase composition of the materials, such as rare earth oxides. Fang et al. reduced the densification rate by doping $\mathrm{Y}_{2} \mathrm{O}_{3}$ and $\mathrm{La}_{2} \mathrm{O}_{3}$ in alumina. ${ }^{1}$ Yang et al. ${ }^{2}$ found that $\mathrm{La}_{2} \mathrm{O}_{3}$ could improve the densification degree and transmittance of transparent alumina ceramics. Wu et $a l^{3}$ reported that the wear resistance of alumina ceramics containing $\mathrm{La}_{2} \mathrm{O}_{3}$ was $43 \%$ higher than without it. Therefore, the distribution of rare earth oxides in alumina has become a topic of concern. The electron probe microanalysis (EPMA) results showed that the rare earth oxides distribution at the grain boundary of alumina transparent ceramics was a nonequilibrium thermodynamic composition distribution. Thompson et al. ${ }^{4}$ studied the distribution of $\mathrm{La}_{2} \mathrm{O}_{3}$ and $\mathrm{Y}_{2} \mathrm{O}_{3}$ in polycrystalline alumina ceramics by secondary ion mass spectrometry (SIMS), and found that $\mathrm{La}^{3+}$ and $\mathrm{Y}^{3+}$ were mainly distributed at the grain boundary and on the surface of the pores. The above results showed that the elemental distribution had an important influence on the structure uniformity, which was also helpful to obtain better ceramics. Therefore, the uniformity of the elemental distribution is an important index to evaluate the properties of ceramics.

So far, many techniques for elemental distribution analysis were developed, mainly SIMS $^{5-8}$, laser ionization mass spectrometry (LIMS) ${ }^{9}$, glow discharge mass spectrometry (GDMS) ${ }^{10}$ and laser ablation inductively coupled plasma mass spectrometry (LAICPMS) ${ }^{11,12}$. Compared with conventional solution-based analytical methods, direct solid analysis by mass spectrometry can provide more efficient analysis without a complicated sample pretreatment.

LA-ICP-MS has become an attractive analytical technique for the direct analysis of solid samples due to its direct analysis of solid samples, in-situ micro area and micro loss analysis, and high sensitivity and low detection limits of MS. It has been used for the determination of micro- and trace elements and the measurement of isotope ratios, as well as in microanalyses, in-depth profiling, 
and elemental imaging. ${ }^{13}$ And imaging has been widely applied in many fields, including geology ${ }^{14}$, biology ${ }^{15-18}$, and the environmental ${ }^{19}$ and material sciences. ${ }^{20-22}$ However, most of the LA-ICP-MS imaging samples should be provided with a planar surface, and there were few reports on curved surface samples. This was mainly the "focus" required in LA-ICP-MS analysis, and the difference of laser focusing would cause laser energy fluctuation resulting in wrong imaging data.

In this work, LA-ICP-MS was used for elemental imaging of the curved surface samples by segmentation and recombination. In addition, the influence of parameters on the lateral resolution, an important index of imaging analysis, were investigated in detail. The developed method was applied to the imaging analysis of lanthanum in alumina ceramic tubes.

\section{EXPERIMENTAL}

A quadrupole-based X Series II ICP-MS system (Thermo Fisher, USA), combined with an NWR-213 laser ablation system (NewWave, USA), was used for imaging analysis. Table 1 summarized the typical experimental parameters. Helium, used as the carrier gas for cell purging, was mixed with argon when introduced into the plasma. The data were drawn into twodimensional images by Iolite software (Iolite 4.0). The alumina ceramic tubes were supplied by Shengnuo Optoeletronic Technology (Qing Hai) Co., Ltd. The tube surface was cleaned with $2 \% \mathrm{HNO}_{3}$ and deionized water, dried, and then fixed in the sample cell with double-sided tape. When rotation of the sample was required, the sample cell needed to be opened, the position marked, and then rotated to the next section for ablation.

\section{RESULTS AND DISCUSSION}

\section{Optimization of LA-ICP-MS parameters}

The optimization process of the LA-ICP-MS imaging analysis conditions mainly includes: (i) minimum limits of detection; (ii) maximum spatial resolution; and (iii) minimum time of analysis. Spatial resolution is divided into horizontal resolution and vertical resolution, which refers to the size of two adjacent points that can be distinguished. In this work, the optimized spatial resolution refers to the lateral resolution.

Laser ablation mode. Elemental imaging can be completed by spot ablation mode or line ablation mode. For spot ablation, the XY stage moves to a location, ablates a few shots, then repeats in a new location until it covers the whole sample. Image blurring can be avoided by leaving enough waiting times between two spots, which are from microseconds to a few seconds (0.1-10 s, depending on the cell volume) to ensure total particulate washout from the cell. Günther et al. developed a low dispersion sample chamber (tube cell), which made an improvement in the imaging
Table 1 Typical Experimental Parameters of LA-ICP-MS Imaging

\begin{tabular}{lclc}
\hline LA parameters & Values & $\begin{array}{l}\text { ICP-MS } \\
\text { parameters }\end{array}$ & Values \\
\hline $\begin{array}{l}\text { Laser } \\
\text { wavelength (nm) }\end{array}$ & 213 & RF power (W) & 1400 \\
$\begin{array}{l}\text { Laser energy } \\
\left(\mathbf{J} / \mathbf{c m}^{2}\right)\end{array}$ & 2.16 & Sampling depth & 150 \\
$\begin{array}{l}\text { Repetition rate } \\
(\text { Hz) }\end{array}$ & 10 & $\begin{array}{l}\text { Signal acquisition } \\
\text { mode }\end{array}$ & TRA \\
$\begin{array}{l}\text { Spot size }(\boldsymbol{\mu m}) \\
\text { Carrying gas } \\
(\text { He) }(\mathbf{L} / \mathbf{m i n})\end{array}$ & 100 & $\begin{array}{l}\text { Dwell time (ms) } \\
\text { Carrier gas (Ar) }\end{array}$ & 10 \\
Sampling cell & $\begin{array}{c}\text { Single } \\
\text { volume }\end{array}$ & $\begin{array}{l}\text { Isotopes } \\
\text { (L) }\end{array}$ & 0.7 \\
\hline
\end{tabular}

capabilities by reduction of the single LA shot duration to $30 \mathrm{~ms}$ (full width at $1 \%$ maximum). ${ }^{23}$ Vanhaecke et $a l .{ }^{24}$ designed a lowdispersion small sample cell embedded in the cobalt sample chamber integrated into LA-ICP-MS and achieved a sub-micron $(0.6 \mu \mathrm{m})$ spatial resolution. Under optimum conditions, single pulse responses with a full width at $10 \%$ of the maximum peak intensity (FW0.1M) of $\sim 1 \mathrm{~ms}$ can be achieved. These low dispersion sample chambers made spot ablation a good choice. For line ablation, the X-Y stage moves continuously in a straight line. Compared with spot ablation, the analysis speed of line ablation is faster and the data processing is simpler, but the disadvantage is that the data are easily affected by the washout time of the sampling cell. Considering the influence of analysis speed and spatial resolution, the line ablation mode was chosen for imaging analysis in this experiment.

Spot size. Generally, spatial resolution is used to describe the number of pixels used to make up an image. In the same physical size, the more pixels, the higher spatial resolution of the image. Thus, the spot size had a big impact on spatial resolution. Typically, the imaging lateral resolution range for minerals, ceramics and other sample types were from 20 to $100 \mu \mathrm{m} .{ }^{25}$ Recent achievements in bio-imaging have led to improved lateral resolutions down to $1 \mu \mathrm{m} .^{23,26,27}$ Small spatial resolution for biological samples is essential to obtain effective information on elemental distribution because the diameter of a single mammalian cell is about or less than $20 \mu \mathrm{m}$. However, low lateral resolution of micron scale is not extremely necessary for surface imaging of large bulk materials in centimeter scale to study the uniformity of elemental distribution, such as doped ceramics or crystal materials. Considering the character of the alumina ceramic tube, analysis time and spatial resolution, the spot size was set to $100 \mu \mathrm{m}$.

In addition, the laser fluence and the repetition rate affect the lateral resolution by increasing or decreasing the signal intensity. Laser fluence should be estimated to obtain enough signals based on the statistically different signal-noise ratio and the energy threshold of the samples. It is usually necessary to control excessive laser fluence to avoid ablating the underlying glass slide in tissue imaging, which was of no concern in the ablation of the 

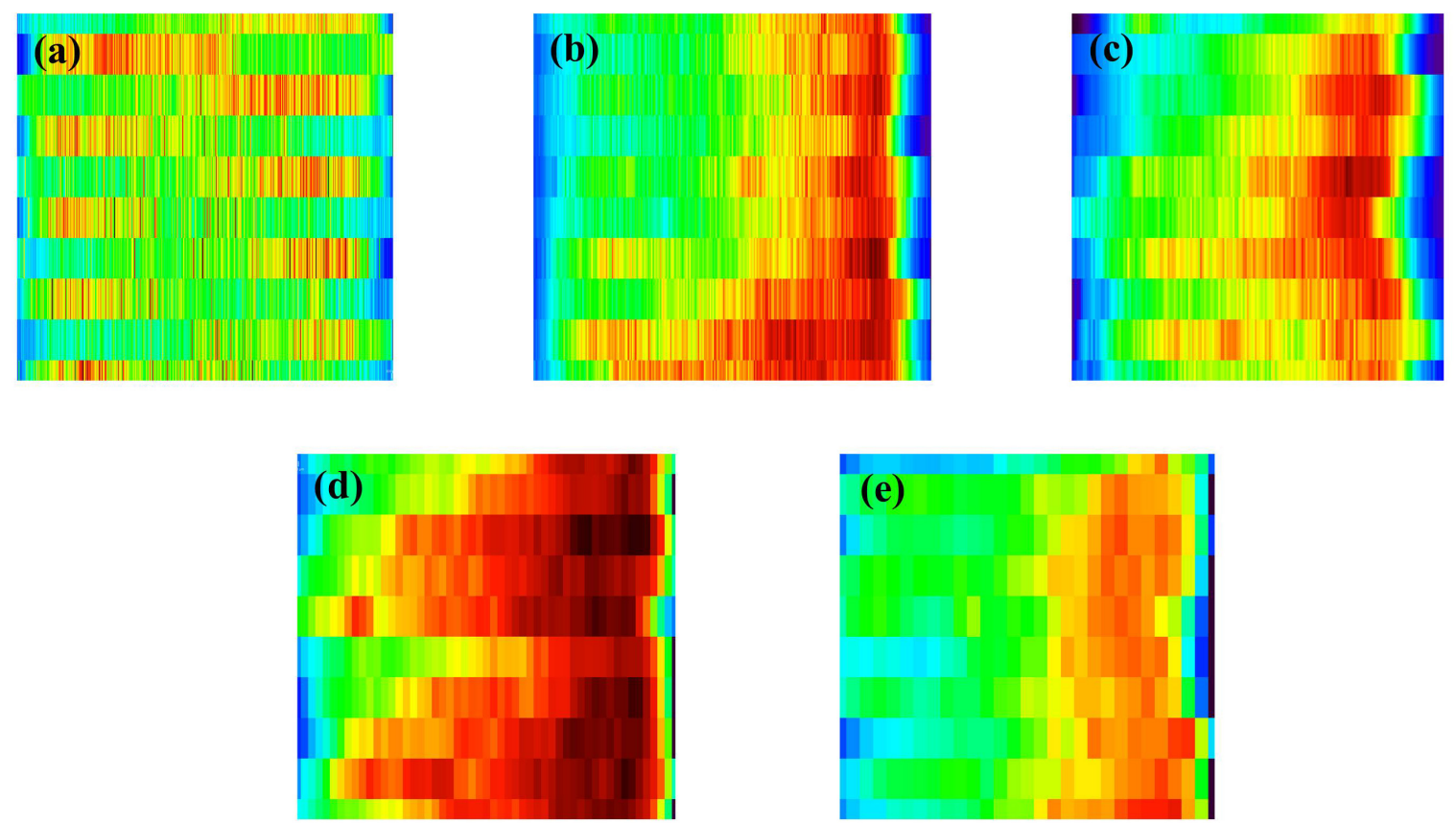

Fig. $1 \mathrm{Al}$ images were obtained at different dwell times (a) $1 \mathrm{~ms}$; (b) $5 \mathrm{~ms}$; (c) $10 \mathrm{~ms}$; (d) $50 \mathrm{~ms}$; (e) $100 \mathrm{~ms}$. Laser spot size: $100 \mu \mathrm{m}$, repetition rate: $10 \mathrm{~Hz}$, scan speed: $100 \mu \mathrm{m} / \mathrm{s}$, and laser energy: $10 \%$.

ceramic samples. The estimation results showed that the laser energy was greater than approximately $2 \mathrm{~J} / \mathrm{cm}^{2}(5 \%$ laser energy and $100 \mu \mathrm{m}$ spot size), the signal and background of lanthanum were significantly different, and the degree of plasma ionization was high, which was obtained by determining the $\mathrm{U} / \mathrm{Th}$ ratio in NIST 610 under the same conditions. The laser fluence of approximately $2.5 \mathrm{~J} / \mathrm{cm}^{2}(10 \%$ laser energy and $100 \mu \mathrm{m}$ spot size $)$ was chosen in this work. The laser repetition rate was also one of the important influencing factors. An increase in laser repetition rate resulting in denser ablation does not improve the spatial resolution of the images because there was not enough time interval to wash out the adjacent laser shot. At higher repetition rates, the signal overlap between adjacent shots will lead to image blurring. A low repetition rate may cause the laser shot not go through the sample completely, so the laser repetition rate will be determined according to the scan speed and washout time in this work.

Consequently, the trade-off among spatial resolution and sampling time of the elemental image of the alumina ceramic were investigated, including the parameters of the laser scan speed, dwell time and washout time.

Washout time. The aerosol generated by each laser shot takes time to traverse the cell, the tubing, the torch before being detected in the detector, known as washout time. The washout time was usually calculated from the transient signals as the time taken by the signal to fall to $1 \%$ of its peak value. Besides the sampling time and scan speed, a washout time of the ablation cell had great influence on the lateral resolution resulting in signal broadening.
Doble's group ${ }^{28}$ research showed that fast scan speeds were applicable for imaging experiments, making the measurements more time-efficient. However, the washout behavior of the used cell plays a significant role for the maximum obtainable scan speed and thus, image quality might suffer from blurring effects.

In this work, washout time as a function of different parameters (He flow rate, dwell time) was assessed by analyzing the Al signal in a commercial sampling cell. A steady decrease in washout times was observed with an increase in He flow rate from $600 \mathrm{~mL} / \mathrm{min}$ $(2.5 \mathrm{~s})$ to $1000 \mathrm{~mL} / \mathrm{min}(1.5 \mathrm{~s})$. For the following experiments, the He flow rate was set at $1000 \mathrm{~mL} / \mathrm{min}$. Considering the relationship between dwell time and signal acquisition, dwell time was also investigated. The results (not given here) showed that dwell time has little effect on washout time, which fluctuated between $1.8 \mathrm{~s}$ and $2.0 \mathrm{~s}$. Therefore, the washout time of a commercial sampling cell used in this experiment was $1.5 \mathrm{~s}-2.5 \mathrm{~s}$, which was comparable to routinely applied ablation cells. Despite the many efforts made, most of the routinely applied ablation cells have an experimental washout time in the order of a few seconds for a $99 \%$ intensity drop from the peak maxima. ${ }^{29}$ For only a few examples it was reported that the washout time was as short as a few milliseconds. ${ }^{19,23,30}$

Dwell time. Quadrupole ICP-MS acquires data for an allocated mass-to-charge ratio $(\mathrm{m} / \mathrm{z})$ for a specified time period, or dwell time, before moving to the next $\mathrm{m} / \mathrm{z}$. This is continued until the data have been acquired for all designated $\mathrm{m} / \mathrm{z}$. Exactly, the quadrupole mass analyzer is not a simultaneous data collection technique, though it is able to rapidly acquire information for each 

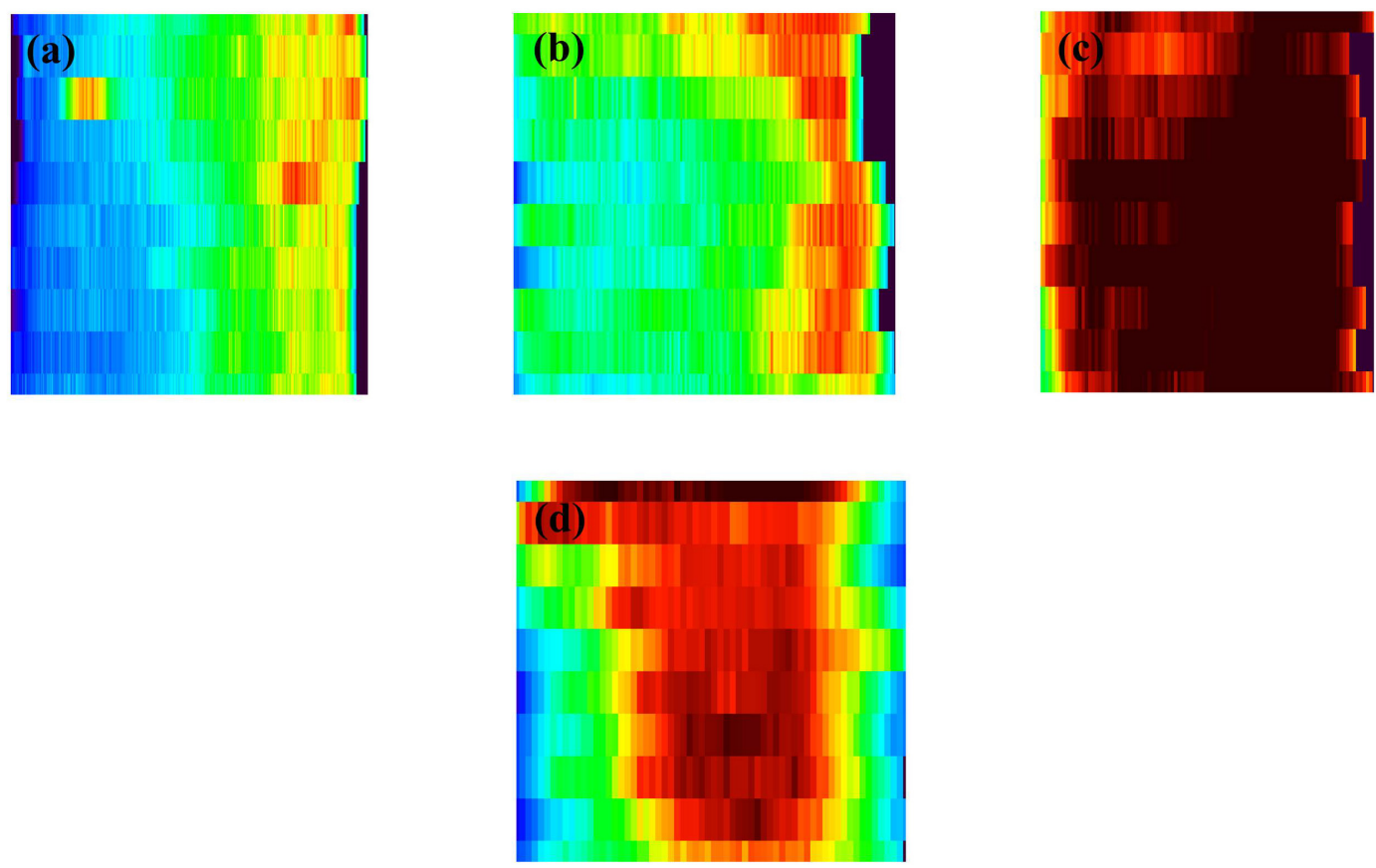

Fig. $2 \mathrm{Al}$ images were obtained at different scan speeds: (a) $50 \mu \mathrm{m} / \mathrm{s}$; (b) $100 \mu \mathrm{m} / \mathrm{s}$; (c) $200 \mu \mathrm{m} / \mathrm{s}$; (d) $400 \mu \mathrm{m} / \mathrm{s}$. Laser spot size: $100 \mu \mathrm{m}$, repetition rate: 10 Hz, laser energy: $10 \%$.

$\mathrm{m} / \mathrm{z}$. In addition, the dead time will produce when the $\mathrm{m} / \mathrm{z}$ is switched, which is the reason that the acquisition time is not equal to the sum of all dwell time of $\mathrm{m} / \mathrm{z}$. Limiting signal experiments were performed using 5 dwell times for each measured mass $(1,5$, 10,50 and $100 \mathrm{~ms}$ ) using $100 \mu \mathrm{m}$ spot size, $100 \mu \mathrm{m} / \mathrm{s}$ scan speed, $10 \mathrm{~Hz}$ repetition rate and $10 \%$ laser energy. The results from Fig. 1 showed that the number of lateral pixels obtained at the dwell times of 1, 5, 10, 50 and $100 \mathrm{~ms}$ was about $60,40,30,10$ and 5 under the same laser ablation conditions, which was obtained by taking the dead time into account. Obviously, more element signal data were detected at a smaller dwell time for each laser spot, resulting in higher lateral resolution. The image with the dwell time of $1 \mathrm{~ms}$ is not clearly, which was mainly due to the overlapping of data caused by the long washout time of the sampling cell. The image with a dwell time of $100 \mathrm{~ms}$ has the image missing in Fig. 1e, which was due to the long dwell time resulting in data loss. The outline of images with dwell time of 5 , 10 and $50 \mathrm{~ms}$ were similar.

Dwell time should be as short as possible but ensure good differentiation between signal and noise to avoid biased intensity. To meet the requirement of statistical difference, the minimum difference between the low error bar of the samples and the high error bar of the background was 0 . The minimum dwell time can be calculated by the following formula:

$$
\begin{gathered}
\left(I_{\text {sam }}-3 * \sigma * I_{\text {sam }}\right)-\left(I_{\mathrm{bkg}}+3 * \sigma * I_{b k g}\right) \geq 0 \\
\sigma=\sqrt{n} / n
\end{gathered}
$$

where $I_{s a m}$ and $I_{b k g}$ were the intensity of the sample and the background, respectively. $\sigma$ was the standard deviation of the signal counts not CPS. The minimum intensity of La was more than 500 and the background signal was less than 100 from test ablation. According to the above formula, the shortest dwell time was about $12 \mathrm{~ms}$. Therefore, combined with the above experimental results, the dwell time chosen was $10 \mathrm{~ms}$.

Scan speed. Shortening the analysis time is mainly determined by the laser scan speed. Kanicky found that the relative broadening of the images was related to enlarging the laser spot and increasing the scan speed as well, while the scan speed affects the broadening more strongly than the laser spot diameter. ${ }^{31}$ The scan speed was investigated in this work and the results are shown in Fig. 2. To make sure the laser hits at least once everywhere in the region of interest, the value of spot size multiplied by repetition rate should be greater than or equal to scan speed, that is, the scan speed should be less than $1000 \mu \mathrm{m} / \mathrm{s}$ in this work. Fig. $2 d$ shows obvious color differences between the middle and the sides, which was due to the inconsistent focus. In addition, there was no obvious broadening at the scan speed of $50-200 \mu \mathrm{m} / \mathrm{s}$ as shown in Fig. 2a-c. It can be seen that the scan speed was higher than $400 \mu \mathrm{m} / \mathrm{s}$, since the laser stage moved too fast to focus properly. Therefore, considering to shortened analysis time, the scan speed was chosen as $200 \mu \mathrm{m} / \mathrm{s}$.

\section{Lanthanum imaging on alumina ceramic tube.}

The difficulty of elemental imaging on an alumina tube lies in the 

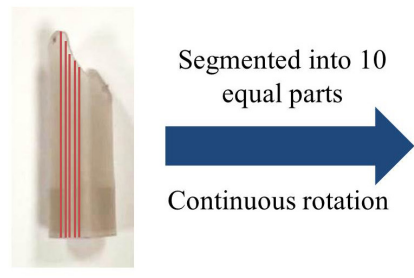

Continuous rotation

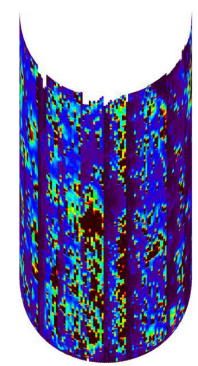

Fig. 3 Lanthanum imaging on alumina ceramic tube.

multi-line focusing of non-planar surfaces. In this work, the La imaging of the alumina ceramic tube was established by segmentation and recombination under the optimized experimental parameters. The focusing range of the tube placed in a flat was investigated. It was found that the optimal range of the tube with an outer diameter of $0.68 \mathrm{~cm}$ used in this experiment was less than $1 \mathrm{~mm}$. According to the formula of arc length and central angle, the semicircular tube to be imaged was segmented into 10 equal parts. After one-part is scanned, slowly rotate to the next until these 10 scans are completed in turn. Finally, the 10 images were recombined in order to form the La map of the aluminum oxide tube by Photoshop software (Fig. 3). The imaging results showed that lanthanum was not uniformly distributed in the alumina ceramic tube.

\section{CONCLUSIONS}

In this study, the influence of the parameters for laser spot size, laser fluence, repetition rate, scan speed, dwell time and washout time on the lateral resolution were investigated in detail. The elemental imaging method for the alumina ceramic tube by LAICP-MS was established by segmentation and recombination to obtain the optimal laser focus. The optimal focusing range of the tube with an outer diameter of $0.68 \mathrm{~cm}$ was determined to be 1 $\mathrm{mm}$. Laser ablating of the tube was achieved by establishing 10 optimal focusing ranges of the tube, and then recombining every image to form the complete elemental maps of the tube. The lanthanum images of the alumina ceramic tube showed that lanthanum was not uniformly distributed in the tube. The results of this study show that LA-ICP-MS is a powerful imaging technology and will be widely used in archaeology and materials science. Future work will focus on rapid elemental imaging of irregularly shaped samples without going through segmentation and recombination.

\section{AUTHOR INFORMATION}

\section{Corresponding Author}

* Z. Wang

Email address: wangzheng@ mail.sic.ac.cn

Notes

The authors declare no competing financial interest.

\section{ACKNOWLEDGMENTS}

This work was supported by the Shanghai Technical Platform for Testing and Characterization on Inorganic Materials (19DZ2290700), Science and Technology Program of Qinghai Province (2019-GX-C37) and Science and Technology Innovation Project of Shanghai Institute of Ceramics.

\section{REFERENCES}

1. J. X. Fang, A. M. Thompson, M. P. Harmer, and H. M. Chan, J. Am. Ceram. Soc., 1997, 80, 2005-2012. https://doi.org/10.1111/j.1151-2916.1997.tb02840.x

2. Q. H. Yang, Z. J. Zeng, J. Xu, H. W. Zhang, and J. Ding, J. Chin. Rare Earth Soc., 2006, 24, 72-75. https://doi.org/10.1016/s1002-0721(06)60068-9.

3. T. Wu, J. Zhou, B. Wu, and W. Li, J. Rare Earths., 2016, 34, 288-294. https://doi.org/10.1016/s1002-0721(16)60027-3.

4. A. M. Thompson, K. K. Soni, H. M. Chan, M. P. Harmer, D. B. Williams, J. M. Chabala, and R. LeviSetti, Chabala and R. Levi-Sett., J. Am. Ceram. Soc., 1997, 80, 373-376. https://doi.org/10.1111/j.1151-2916.1997.tb02840.x

5. Z. P. Li and K. Hirokawa, Anal. Sci., 2003, 19, 1231-1238. https://doi.org/10.2116/analsci.19.1231.

6. B. Cerqueira, D. Arenas-Lago, M. L. Andrade, and F. A. Vega, Geoderma, 2015, 251-252, 65-77. https://doi.org/10.1016/j.geoderma.2015.03.026.

7. J.-T. Li, J. Swiatowska, A. Seyeux, L. Huang, V. Maurice, S.-G. Sun, and P. Marcus, J. Pow. Sources., 2010, 195, 8251-8257. https://doi.org/10.1016/j.jpowsour.2010.07.043.

8. A. G. Adriaens, J. D. Fassett, W. R. Kelly, D. S. Simons, and F. C. Adams, Anal. Chem., 2002, 64, 2945-2950. https://doi.org/10.1021/ac00047a012.

9. V. Grimaudo, P. Moreno-Garcia, A. Riedo, M. B. Neuland, M. Tulej, P. Broekmann, and P. Wurz, Anal. Chem., 2015, 87, 2037-41. https://doi.org/10.1021/ac504403j.

10. N. Jakubowski, T. Prohaska, L. Rottmann, and F. Vanhaecke, J. Anal. At. Spectrom., 2011, 26, 693-726. https://doi.org/10.1039/c0ja00161a.

11. T. Ubide, C. A. McKenna, D. M. Chew, and B. S. Kamber, Chem. Geol., 2015, 409, 157-168. https://doi.org/10.1016/j.chemgeo.2015.05.020.

12. Y. Li, W. Guo, Z. Hu, L. Jin, S. Hu, and Q. Guo, J. Agric. Food. Chem., 2019, 67, 935-942. https://doi.org/10.1021/acs.jafc.8b05479. 
13. B. Fernández, F. Claverie, C. Pécheyran, O. F. X. Donard, and F. Claverie, TrAC-Trends in Anal. Chem., 2007, 26, 951-966. https://doi.org/10.1016/j.trac.2007.08.008.

14. V. Balaram, Geolog. J., 2020. https://doi.org/10.1002/gj.4005.

15. O. M. Voloaca, C. J. Greenhalgh, L. M. Cole, M. R. Clench, A. J. Managh, and S. L. Haywood-Small, Rapid Commun. Mass Spectrom., 2020, 34, e8906. https://doi.org/10.1002/rcm.8906.

16. M. Tulej, M. Iakovleva, I. Leya, and P. Wurz, Anal. Bioanal. Chem., 2011, 399, 2185-200. https://doi.org/10.1007/s00216-010-4411-3.

17. A. Lores-Padin, B. Fernandez, L. Alvarez, H. Gonzalez-Iglesias, I. Lengyel, and R. Pereiro, Talanta, 2021, 221， 121489. https://doi.org/10.1016/j.talanta.2020.121489.

18. Q. Li, Z. Wang, Y. Chen, and G. Zhang, Metallomics, 2017, 9, 1150-1156. https://doi.org/10.1039/c7mt00132k.

19. P. Bohleber, M. Roman, M. Šala, and C. Barbante, J. Anal. At. Spectrom., 2020, 35, 2204-2212. https://doi.org/10.1039/d0ja00170h.

20. G. Zhang, Q. Li, Y. Zhu, and Z. Wang, Spectrochim. Acta B., 2018, 145, 51-57. https://doi.org/10.1016/j.sab.2018.04.004.

21. L. Guo, Q. Li, Y. Chen, G. Zhang, Y. Xu, and Z. Wang, J. Anal. At. Spectrom., 2020, 35, 1441-1449. https://doi.org/10.1039/D0JA00054J.

22. Y. Zhu, C. Li, M. Chen, G. Zhang, C. Mao, H. Kou, and Z. Wang, At. Spectrosc., 2019, 40, 49-54. https://doi.org/10.46770/as.2019.02.003.

23. H. A. Wang, D. Grolimund, C. Giesen, C. N. Borca, J. R. Shaw-Stewart, B. Bodenmiller, and D. Gunther, Anal. Chem.,
2013, 85, 10107-16. https://doi.org/10.1021/ac400996x.

24. S. J. M. Van Malderen, T. Van Acker, and F. Vanhaecke, Anal. Chem., 2020, 92, 5756-5764. https://doi.org/10.1021/acs.analchem.9b05056.

25. B. Paul, J. D. Woodhead, C. Paton, J. M. Hergt, J. Hellstrom, and C. A. Norris, Geostand. Geoanal. Res., 2014, 38, 253-263. https://doi.org/10.1111/j.1751-908X.2014.00270.x.

26. C. Giesen, H. A. O. Wang, D. Schapiro, N. Zivanovic, A. Jacobs, B. Hattendorf, P. J. Schueffler, D. Grolimund, J. M. Buhmann, S. Brandt, Z. Varga, P. J. Wild, D. Guenther, and B. Bodenmiller, Nat. Met., 2014, 11, 417-422. https://doi.org/10.1038/nmeth.2869.

27. Z. Liang, S. Zhang, X. Li, T. Wang, Y. Huang, W. Hang, Z. Yang, J. Li, and Z. Tian, Sci. Adv., 2017, 3, eaaq1059. https://doi.org/10.1126/sciadv.aaq1059.

28. J. Lear, D. Hare, P. Adlard, D. Finkelstein, and P. Doble, J. Anal. At. Spectrom., 2012, 27, 159-164. https://doi.org/10.1039/c1ja10301f.

29. S. J. M. Van Malderen, A. J. Managh, B. L. Sharp, and F. Vanhaecke, J. Anal. At. Spectrom., 2016, 31, 423-439. https://doi.org/10.1039/c5ja00430f.

30. D. N. Douglas, A. J. Managh, H. J. Reid, and B. L. Sharp, Anal. Chem., 2015, 87, 11285-11294. https://doi.org/10.1021/acs.analchem.5b02466.

31. T. Vaculovič, T. Warchilová, Z. Čadková, J. Száková, P. Tlustoš, V. Otruba, and V. Kanický, Appl. Surf. Sci., 2015, 351, 296-302. https://doi.org/10.1016/j.apsusc.2015.05.136. 